PERSONAL, FAMILIAL AND SOCIAL CHARACTERISTICS OF INFANTS WITH ACUTE RESPIRATORY INFECTION

N.M. Lakeh, R. Pourmohammad, A. Ghanbari, A. Pasha, S. Asiri, L. Mirhadian

Guilan University Medical Sciences, Rasht, Iran

Background and aims: Acute Respiratory Infection (ARI) is the most common cause of mortality in children under five years of age in Iran. Its treatment and care costs a lot and if left untreated, can cause irreversible side effects. Identifying predictive factors are essential for proper prevention. This study aims to determine the personal, familial and social characteristics of infants with ARI.

Methods: This descriptive study included 375 infants up to 12 months of age which covered $0.7 \%$ of all infants in Rasht, Iran who were chosen by simple sampling. Parents were asked about their infants regarding $A R I$ in past two weeks and finally 149 ill infants and 220 well children were assessed. The data collection tool included a self-made questionnaire and data were analyzed using Chisquare and Logit by soft ware SPSS10.

Results: A significant relationship between ARI and personal characteristics such as age, rank of children , familial characteristics, mothers under 25 years of age, parents education, mean monthly income, residential housing, parents smoking more than 10 cigarettes daily, house resident with $A R I$, and social characteristics like sibling in school or day care center, no medical insurance and living in houses $<70 \mathrm{~m} 2$ with $>4$ family members was indicated.

Conclusions: To decrease ARI in infants, exposure to others must be limited in second six months of life, no more than four people in the house, satisfactory economic condition, educated parents, healthy smoking, knowledge of ARI transmission, and proper housing are suggested.

\section{RANDOMIZED TRIAL (RCT) ON MILKING OF THE CORD VERSUS SLIGHT DELAY OF CORD CLAMPING IN PRETERMS (VLBW): EFFECTS ON CIRCULATON}

H. Rabe ${ }^{1}$, A. Jewison ${ }^{2}$, R. Fernandez Alvarez ${ }^{1}$, D. Stilton ${ }^{1}$, R. Bradley ${ }^{3}$, D. Holden ${ }^{3}$, Brighton Perinatal Study Group

${ }^{1}$ Neonatology, Brighton and Sussex University Hospitals, ${ }^{2}$ Brighton \& Sussex Medical School, ${ }^{3}$ Obstetrics, Brighton \& Sussex University Hospitals NHS Trust, Brighton, UK

Background: RCTs demonstrated a slight delay of 30 s in clamping the cord benefits VLBW by reducing intraventricular hemorrhages and blood transfusion. Birth attendees hesitate to wait for 30 s, therefore milking of the cord has been reported in one trial. Aim: To evaluate the circulatory effects of four times milking the cord (MilkG) versus a slight delay in clamping the cord of 30s (ClampG) in VLBW < 33 weeks.

Methods: Prospective, single centre study, inborn singletons $<33$ weeks. Data analysis for significant differences was performed with Wilcoxon test.

Results: 30 VLBW were randomized to the ClampG (median birth weight 1200g (525-1975), median gestational age 29w (24-32)) and 28 to the MilkG (median birth weight 1170g (444-2245), median gestational age 30w (24-32)). Values for blood pressure (median BP, mmHg, Q25, Q75) are summarized in the table for the first $72 \mathrm{~h}$ of life. No significant differences were found (all $p>0.05$ ).

\begin{tabular}{|c|c|c|c|c|c|c|c|c|}
\hline $\begin{array}{l}\text { Median } \\
\text { (Q25 } \\
\text { Q75) }\end{array}$ & $\begin{array}{l}\text { BP } \\
1 \mathrm{~h}\end{array}$ & $\begin{array}{l}\text { BP } \\
4 \mathrm{~h}\end{array}$ & $\begin{array}{l}\text { BP } \\
6 \mathrm{~h}\end{array}$ & $\begin{array}{l}\mathrm{BP} \\
12 \mathrm{~h}\end{array}$ & $\begin{array}{l}\text { BP } \\
24 h\end{array}$ & $\begin{array}{l}\mathrm{BP} \\
48 \mathrm{~h}\end{array}$ & $\begin{array}{l}\mathrm{BP} \\
72 \mathrm{~h}\end{array}$ & $\begin{array}{l}\text { BP } \\
120 \mathrm{~h}\end{array}$ \\
\hline MilkG & $\begin{array}{l}38 \\
(27 ; \\
40)\end{array}$ & $\begin{array}{l}36 \\
(32 ; \\
42)\end{array}$ & $\begin{array}{l}38 \\
(35 ; \\
48)\end{array}$ & $\begin{array}{l}39 \\
(36 ; \\
44)\end{array}$ & $\begin{array}{l}44 \\
(35 ; \\
48)\end{array}$ & $\begin{array}{l}44 \\
(37 ; \\
48)\end{array}$ & $\begin{array}{l}43 \\
(36 ; \\
46)\end{array}$ & $\begin{array}{l}47 \\
(41 ; \\
54)\end{array}$ \\
\hline ClampG & $\begin{array}{l}31 \\
(27, \\
37)\end{array}$ & $\begin{array}{l}33 \\
(28 ; \\
36)\end{array}$ & $\begin{array}{l}34 \\
(31 ; \\
39)\end{array}$ & $\begin{array}{l}37 \\
(34 ; \\
40)\end{array}$ & $\begin{array}{l}37 \\
(33 ; \\
41)\end{array}$ & $\begin{array}{l}39 \\
(37 ; \\
48)\end{array}$ & $\begin{array}{l}40 \\
(32 ; \\
47)\end{array}$ & $\begin{array}{l}46 \\
(40 ; \\
50)\end{array}$ \\
\hline
\end{tabular}

[Blood Pressure (BP)]

Conclusions: Our study demonstrates that MilkG could substitute ClampG in VLBW. The blood transfer from the placenta is similar with both approaches supporting postnatal circulatory adaptation. 